\title{
Use of the relative indicator for estimation of railway blocks capacity
}

\author{
Sergei Bessonenko, ${ }^{1, *}$, and Ekaterina $\mathrm{Klimova}^{1}$, and Aleksei Dementyev ${ }^{1}$ \\ ${ }^{1}$ Siberian Transport University, 630049 Novosibirsk, Russia
}

\begin{abstract}
Capacity of railway blocks and sections is one of the most important parameters of railway transport operation. The purpose of the study is to find a universal parameter of railway blocks and sections capacity that would allow maximum use of the reserves available. This paper proposes to use "partial capacity filling factors", which are defined as the ratio of the changed capacity factor to the existing value, as a relative indicator. The methodology of application of this indicator has been elaborated, examples of calculations have been provided. There are nomograms in the paper that allow determining the maximum number of trains that can be passed through the section taking into consideration all conditions of operation.
\end{abstract}

\section{Introduction}

Correct estimation of the capacity of railway blocks and sections allows ensuring the maximum traffic for each block. At the present stage of the development of the methodology for assessing and analyzing the capacity, domestic and foreign scientists use various methods [1] based on the following: mathematical dependencies for set infrastructure parameters and parameters of the train traffic arrangement system (analytical methods) $[2,3]$; determination of the change in capacity with variation of the infrastructure parameters and parameters of the train traffic arrangement system, taking into consideration possible delays of trains (parametric methods) [4, 5, 6, 7]; transportation process parameters optimization principles $[8,9]$; simulation of a railway block operation [7, 9, 11]. Absolute values or capacity filling factors, which take into account the initial parameters considered, for example $[12,13]$, are used with the existing estimation and analysis methods.

Railway operation conditions often require rapid estimation of the change in the line capacity value by the resulting value. The value of this indicator depends on many initial parameters: intervals between stations and trains, block usage time, duration of provision of the technological "window", number of trains of various categories, coefficients of removal of freight trains with other categories. With that, such parameter as the infrastructure reliability factor that depends on the number of main tracks in the block and the thrust type is assumed to be conditionally constant.

The purpose of the study is to search for a universal indicator for estimating railway blocks capacity in conditions of changing the initial parameters. The subject of the study is

\footnotetext{
*Corresponding author: bessonenkosa@mail.ru
} 
railway blocks capacity, the object of the study is railway blocks, sections and operating domains. The novelty of this study consists in the use of a relative indicator that depends on the minimum set of variable parameters.

\section{Research methods}

At present, determination of intervals between stations and trains and of the railway section capacity is performed in accordance with the applicable Instructions $[114,2]$. The final result of the calculations is the capacity filling factor that shows the proportion of scheduled graph threads occupied by real trains. Factor analysis of the effect of the following initial parameters for the i-th version of the block operation on the capacity filling factor has been performed within the scope of the study:

1) time parameter that characterizes the type of the train traffic schedule used $T_{i}$ (for example, for single-track blocks, schedule period, $T_{f r}^{i}$, for double-track blocks, the estimated interval between trains in the package, $I_{p}^{i}$ ), minutes;

2) estimated freight trains traffic parameters - $N_{f r}^{i}$, passenger trains traffic parameters - $N_{p s}^{i}$, etc., of the k-th category $N_{k}^{i}$;

3) coefficient of freight trains removal by passenger trains, $\varepsilon_{p s}^{i}$, etc., of the k-th category $\varepsilon_{k}^{i}$

4) duration of provisioning of technological infrastructure breaks, $t_{\text {tech }}^{i}$, minutes.

It is proposed to use the relative indicator of " $k_{r . i}$ ", the quotient of capacity filling factors as the ratio between the changed capacity filling factor and the existing value" to estimate the effect of the initial parameters on the final result. The indicator shall be calculated by the following formula:

$$
k_{r . i}=\frac{k_{c h}}{k_{\text {exis }}},
$$

where $k_{c h}, k_{\text {exis }}$ are the values of the capacity filling factor for new (changed) and existing railway block operation conditions, respectively.

This indicator is a dimensionless value and reflects how many times the block capacity filling factor will change with the change in the initial parameters.

With that, all calculations are performed regarding the initial conditions that correspond to the minimum set of parameter values.

Thus, the generalized formula for calculation of the relative indicator in conditions of changing of all the aforementioned initial parameters will take the following form:

$$
k_{r . i}=\frac{N_{n}^{c h} \cdot N_{H}^{e x i s}}{N_{n}^{e x i s} \cdot N_{H}^{c h}}=\frac{\left(1440-t_{\text {tech }}^{\text {exis }}\right) \cdot T_{c h} \cdot\left(N_{f r}^{c h}+\varepsilon_{p s}^{c h} \cdot N_{p s}^{c h}+\sum \varepsilon_{k}^{c h} \cdot N_{k}^{c h}\right)}{\left(1440-t_{\text {tech }}^{c h}\right) \cdot T_{\text {exis }} \cdot\left(N_{f r}^{\text {exis }}+\varepsilon_{p s}^{\text {exis }} \cdot N_{p s}^{\text {exis }}+\sum \varepsilon_{k}^{\text {exis }} \cdot N_{k}^{\text {exis }}\right)},
$$

where $N_{n}^{i}$ is the required capacity for the i-th variant of operation of the railway block, trains or pairs of trains;

$N_{H}^{i}$ is the existing capacity for the i-th variant of operation of the railway block, trains or pairs of trains.

The following are special cases: 
A) change of the existing blocks capacity as a result of varying of the following:

- the time parameter and the duration of provisioning of technological "windows":

$$
k_{r . i}=\frac{N_{H}^{\text {exis }}}{N_{H}^{c h}}=\frac{\left(1440-t_{\text {tech }}^{\text {exis }}\right) \cdot T_{c h}}{\left(1440-t_{\text {tech }}^{c h}\right) \cdot T_{\text {exisi }}},
$$

- the time parameter:

$$
k_{r . i .}=\frac{T_{c h}}{T_{\text {exis }}},
$$

- the duration of provisioning of technological "windows":

$$
k_{r . i}=\frac{\left(1440-t_{\text {tech }}^{\text {exis }}\right)}{\left(1440-t_{\text {tech }}^{c h}\right)} ;
$$

B) change of the required blocks capacity as a result of varying of the following:

- the number of trains of various categories and the freight trains removal coefficients:

$$
k_{r . i}=\frac{N_{n}^{c h}}{N_{n}^{\text {exis }}}=\frac{N_{f r}^{c h}+\varepsilon_{p s}^{c h} \cdot N_{p s}^{c h}+\sum \varepsilon_{k}^{c h} \cdot N_{k}^{c h}}{N_{f r}^{\text {exis }}+\varepsilon_{p s}^{\text {exis }} \cdot N_{p s}^{\text {exis }}+\sum \varepsilon_{k}^{\text {exis }} \cdot N_{k}^{\text {exis }}},
$$

- the number of trains of various categories:

$$
k_{r . i .}=\frac{N_{f r}^{c h}+\varepsilon_{p s}^{e x i s} \cdot N_{p s}^{c h}+\sum \varepsilon_{k}^{\text {exis }} \cdot N_{k}^{c h}}{N_{f r}^{\text {exis }}+\varepsilon_{p s}^{e x i s} \cdot N_{p s}^{\text {exis }}+\sum \varepsilon_{k}^{\text {exis }} \cdot N_{k}^{\text {exis }}},
$$

- the freight trains removal coefficients:

$$
k_{r . i}=\frac{N_{f r}^{\text {exis }}+\varepsilon_{p s}^{c h} \cdot N_{p s}^{\text {exis }}+\sum \varepsilon_{k}^{c h} \cdot N_{k}^{\text {exis }}}{N_{f r}^{\text {exis }}+\varepsilon_{p s}^{\text {exis }} \cdot N_{p s}^{\text {exis }}+\sum \varepsilon_{k}^{\text {exis }} \cdot N_{k}^{\text {exis }}} .
$$

The methodology described was used to perform calculations to estimate the use of the capacity of a number of railway blocks and sections. The calculated data showed that a more efficient use of capacity reserves was possible in a number of cases.

A conditional railway section, the characteristics of which are as close as possible to the real railway line is adopted as the object of approbation in the article: a double-track section equipped with automatic block system, electrified, only allows two categories of trains, namely, freight and passenger trains.

See the characteristics of changes in the initial values in Table 1.

Table 1. Characteristics of changes in the initial values.

\begin{tabular}{|c|c|c|c|c|}
\hline Initial parameter & UOM & Minimum value & Maximum value & $\begin{array}{c}\text { Step of } \\
\text { changing }\end{array}$ \\
\hline $\begin{array}{c}\text { calculated interval between } \\
\text { freight trains, minutes }\end{array}$ & $\min$ & 7 & 11 & 1 \\
\hline $\begin{array}{c}\text { calculated traffic intensity of } \\
\text { freight trains }\end{array}$ & train & 40 & 90 & 10 \\
\hline $\begin{array}{c}\text { calculated traffic intensity of } \\
\text { passenger trains }\end{array}$ & train & 5 & 30 & 5 \\
\hline $\begin{array}{c}\text { coefficient of removal of } \\
\text { freight trains by passenger } \\
\text { trains }\end{array}$ & - & 1 & 5 & 0.1 \\
\hline
\end{tabular}

\section{Results}

The study results showed that the dependence of the quotient of capacity filling factors (or the relative indicator) 
A) only on the time parameter (design interval between trains ) is direct, linear, and proportional, i.e., as value $I_{p}$ is increased by 2 times, value $k_{o . n}$ is increased by 2 times;

B) only on the "window" duration is direct, non-linear, and non-proportional;

C) on other possible cases of changing of the initial parameters is direct, linear, and non-proportional.

Nomograms for the following special cases were built as an example that illustrates the dependency of the relative indicator on the initial parameters:

- in conditions of the growth in the estimated number of freight trains with the fixed number of passenger train equal to 15 (Fig. 1);

- in conditions of the growth in the number of passenger trains with the fixed number of freight train equal to 60 (Fig. 2).

In both cases, the coefficient of removal of freight trains by passenger trains also varies.

Besides, horizontal lines on the graphs show the limiting values of the permissible capacity filling factor referred to the initial value of the section capacity filling factor. This makes it possible to determine the limiting values of the removal coefficient and/or the number of trains, provided that the capacity filling factor for this variant of combinations of parameters does not exceed the limiting value.

For example, with the freight trains traffic intensity of 50 and the design interval between trains of 10 minutes, reliable passing of trains through the section is only ensured if the coefficient of removal of freight trains by passenger trains does not exceed the value of 4. Otherwise, the absolute value of the capacity filling factor will exceed the permissible value ( 0.99 for double-track blocks).

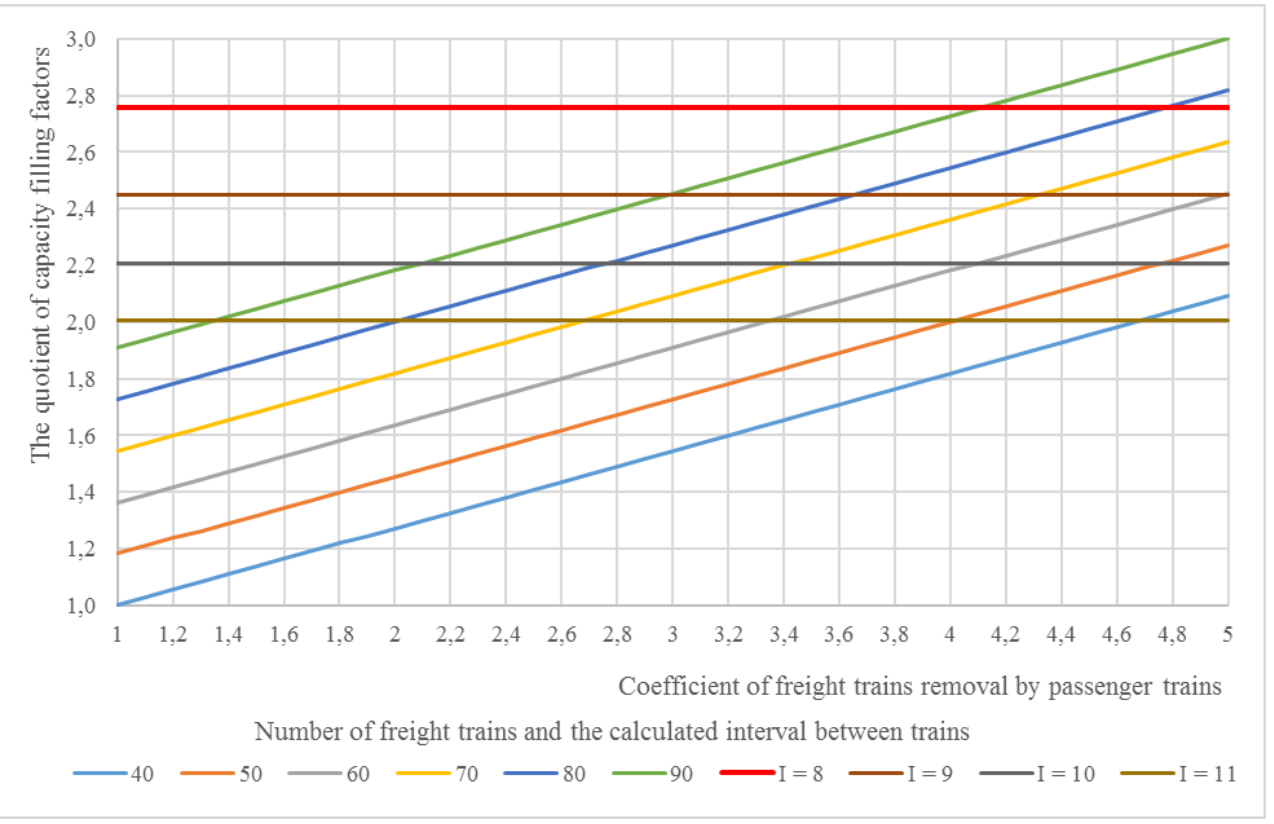

Fig. 1. Graphs of dependency of the relative indicator on changes in removal coefficients with the variable number of freight trains and the fixed number of passenger trains (15 trains).

However, it must be noted here that the interval between trains in the package must be taken into consideration when calculating the absolute value of the capacity loss due to increasing of the removal coefficient, as it affects the existing capacity of the section.

The following are initial conditions on the graphs presented: 
- for Figure 1: the number of passenger trains is 15 , the number of freight trains is 40 , the coefficient of removal of freight trains by passenger trains is 1 ;

- for Figure 2: the number of passenger trains is 5, the number of freight trains is 60 , the coefficient of removal of freight trains by passenger trains is 1 .

Graphs allow quick determining the number of times by which the capacity filling factor will grow with increasing of the coefficient of removal of freight trains by passenger trains (with the fixed number of freight and passenger trains).

With that, in conditions of changing the number of freight trains, the graph threads will be parallel to each other at the same distance (Fig.1). With changes in the number of passenger trains, the graph threads will be crossed in the negative zone of the coefficient of removal of freight trains by passenger trains (Fig.2).

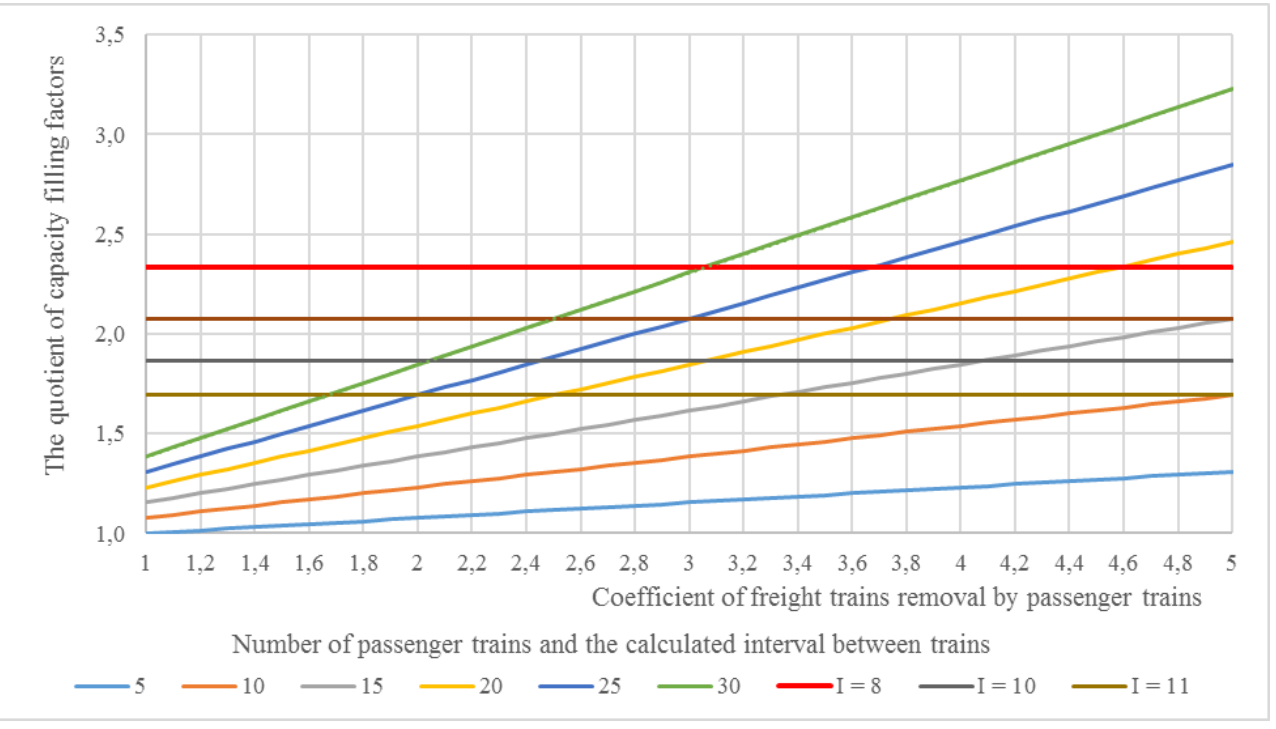

Fig. 2. Graphs of dependency of the relative indicator on changes in removal coefficients with the variable number of passenger trains and the fixed number of freight trains (60 trains).

In conditions of transition from the parallel graph type to the non-parallel type, the coefficient of removal of freight trains by passenger trains may be changed from 1 to 2.5 , which corresponds to the quotient of capacity filling factors equal to 1.409 (Fig.1, with 40 freight trains and 15 passenger trains. It means that the required capacity will grow by 1.409 times, from the value of 55 trains to the value of 77.5 trains, the capacity filling factor will change from 0.359 to 0.506 with the interval between trains in the package equal to 8 minutes.

In conditions of increasing of the coefficient of removal of freight trains by passenger trains from 1.5 to 2.5 , the quotient of capacity filling factors will increase from 1.136 to 1.409. It means that the required capacity will grow by $1.409 / 1.136=1.24$ times, from the value of 62.5 trains to the value of 77.5 trains, the capacity filling factor will change from 0.359 to 0.506 .

Besides, the graphs presented allow determining the change in the capacity filling factor in the case of changing of both parameters For example, the first condition corresponds to 10 passenger trains with the removal coefficient equal to 3 , the second condition corresponds to 15 passenger trains with the removal coefficient equal to 2 . Figure 2 is used to determine the change in the filling factor regarding the initial conditions (the number of passenger trains is 5 , the number of freight trains is 60 , the coefficient of removal of freight 
trains by passenger trains is 1). In accordance with the first condition, it is 1.385 , in accordance with the second condition, it is also 1.385. I.e., the specified combinations of the initial parameters have equal values for the capacity filling factors and the transition from one variant to the other one will be equivalent and will not cause an increase in the capacity filling factor.

The graph of changing of the coefficient of removal of freight trains by high-speed trains from 1 to 9 with the number of passenger trains of 25, the coefficient of removal of freight trains by passenger trains equal to 2 and the number of freight trains of 60 was built for modeling the change in the capacity in conditions of introduction of high-speed passenger trains (Fig.3).

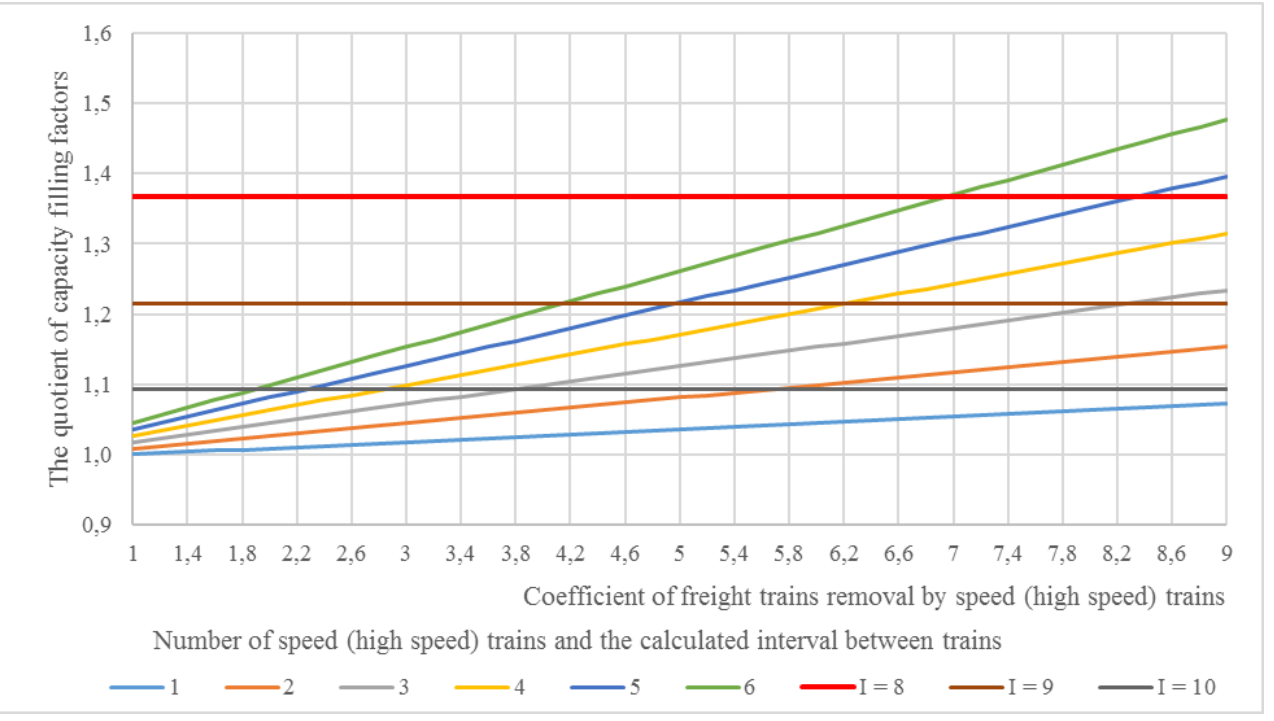

Fig. 3. Graphs of dependency of the relative indicator on changes in removal coefficients with the variable number of high-speed trains and the fixed number of passenger trains ( 25 trains) and freight trains (60 trains).

The graph built shows that if 2 high-speed trains run on the section, the removal coefficient must not exceed 5.6, if the design interval between trains is 10 minutes. Otherwise, the absolute value of the capacity filling factor will exceed the permissible value. No reliable passing of trains through the section will be ensured.

Besides, the graph allows determining the maximum values of the number of highspeed trains and removal coefficients on condition of provision of reliable passing of trains through the block, section or the operating domain. With the design interval between trains equal to 8 minutes, the maximum number of high-speed trains is 6 with the removal coefficient of not more than 6.9.

\section{Conclusion}

The paper proposes a new relative indicator for estimating railway blocks capacity - the quotient of the capacity filling factors. The use of the relative indicator allows estimating the change in railway blocks capacity with the change in the number of trains and the intervals between them, including the conditions of circulation of high-speed passenger trains and during provisioning of technological "windows" of various duration. 
The use of the proposed indicator allows making simple calculation, on the basis of which graphs can be developed. The graphs are used to determine the limiting values of freight and passenger trains on the block as well as intervals between them on condition of reliable passing of trains through the section. This indicator is universal and can be used in estimation of the capacity of single-track and double-track blocks with various technical equipment and schedule types. Its application will allow maximum use of the capacity reserves, which will cause significant improvement of railway transport operation. The results obtained may be used in all software and hardware packages for development of train traffic schedules.

\section{References:}

1. S.A. Branishtov, A.M. Shirvanyan, D.A. Tumchenok C.A. Браништов, Information and Control Systems, 5, 51 - 57 (2014). (in Russian)

2. Instrukcija po raschetu nalichnoj propusknoj sposobnosti zheleznyh dorog: utv. OAO «RZD» 10.11.2010 [Instruction for the calculation of the available railway capacity] (Tehinform, Moscow, 2011). (in Russian)

3. UIC Code 406. Capacity (International Union of Railways (UIC), Paris, 2013).

4. A.M. Makarochkin, Yu.V. Dyakov, Ispol'zovanie i razvitie propusknoj sposobnosti zheleznyh dorog [Use and development of railway capacity] (Transport, Moscow, 1981). (in Russian)

5. I.T. Kozlov, Propusknaja sposobnost' transportnyh sistem [Capacity of transport systems] (Transport, Moscow, 1985). (in Russian)

6. Y.C. Lai, PhD-thesis, University of Illinois, Urbana-Champaign, 2008.

7. S.A. Branishtov, A.M. Shirvanyan, D.A. Tumchenok, Information and Control Systems, 6, 68 - 74 (2014). (in Russian)

8. R. Lusby, J. Larsen, M. Ehrgott, D. Ryan, OR Spectrum, 3, 843 - 883 (2009).

9. J. Yuan, I.A. Hansen, Transportation research. Part B: methodological, Vol. 41(2), $202-217$ (2007).

10. J. Pachl, Railway operation and control (VTD rail publishing, Mountlake Terrace (USA), 2015.

11. V.S. Timchenko, Informatics: Problems, methodology, technologies, Proceedings of the XVI International scientific conference, Voronezh, 502 - 506 (2016). (in Russian)

12. A. Lindfieldt, Doctoral thesis, KTH Royal Institute of Technology, Stockholm, 2015.

13. H. Pouryousef, P. Lautala, T. White, Journal of Modern Transportation, 23(1), 30 - 42, (2015).

14. CD-361. Instruction for the determination of station and inter-train intervals (Tehinform, Moscow, 1995). (in Russian) 